\title{
Determination of the activation energy of silicone rubbers using different kinetic analysis methods
}

\author{
OU Huibin SAHLI Mohamed BARRIERE Thierry ${ }^{\mathrm{a}}$ and GELIN Jean-Claude \\ FEMTO-ST Institute / Applied Mechanics Department, 24 rue de l'Epitaphe, 25000 Besançon, France
}

\begin{abstract}
The solidification of silicone rubbers is a crosslinking reaction called vulcanization. It follows that the physical and mechanical properties of silicone rubbers increase significantly due to the growth of molecular weight and were affected strongly by the vulcanization process, such as the temperatures and times for curing. In this study, the kinetics of the crosslinking reaction of silicone rubbers was investigated by two current techniques: differential scanning calorimeter (DSC) and oscillating disk rheometry (ODR). From the kinetic experimental data, different kinetic analysis methods were used to determine the activation energy of silicone rubbers, such as the Kissinger, the Ozawa, the Friedman, the Flynn-Wall-Ozawa, the Kissinger-Akahira-Sunose and the integral methods. The results show the influence of the chemical composition of silicone rubbers, the current technique used and the applied kinetic analysis methods on the activation energy and the evolution of activation energy during the crosslinking reaction.
\end{abstract}

\section{Introduction}

Silicone rubbers is a specific category of rubbery material, which have many interesting physical and chemical properties, such as good thermal, chemical and mechanical stabilities, good biocompatibility and high elasticity [1]. These unique properties have resulted silicone rubbers to be used in a wide variety of field of application in the industries: aeronautic and aerospace, automotive and transport, electrical and electronic, health and medical, building and construction [2]

Silicone rubber is a thermoset elastomer, mainly based on polydimethylsiloxane (PDMS) and solidified exothermally by a crosslinking reaction called vulcanization. The vulcanization process has a crucial influence on the performance and quality of the final product of silicone rubber. A suitable vulcanization process can improve the properties of silicone rubbers, such as the tear strength, the elongation at break, the hardness and the compression modulus [3].

To optimize and improve the properties of silicone rubbers, the choice of vulcanization process parameters is particularly important, such as the vulcanization temperature and time. In this investigation, two current techniques DSC and ODR were used to characterize the evolution of the crosslinking reaction of silicone rubbers in different heating cycle. In DSC measurement, the vulcanization degree is related to the heat released during the crosslinking reaction. Otherwise, in ODR measurement, the vulcanization degree is attached to the evolution of the elastic modulus. From the experimental data, several kinetic methods were used to determine the activation energy of silicone rubbers following the evolution of crosslinking reaction during the vulcanization process.

\section{Theoretical}

During the crosslinking reaction of silicone rubbers, the reaction rate $\mathrm{d} \alpha / \mathrm{dt}$ is assumed to be a linear function of the rate constant $\mathrm{k}(\mathrm{T})$ and a function of the vulcanization degree $f(\alpha)[4]$ :

\footnotetext{
${ }^{\mathrm{a}}$ Corresponding author: thierry.barriere@univ-fcomte.fr
}

$$
\frac{d \alpha}{d t}=k(T) f(\alpha)=k_{0} \exp \left(-\frac{E_{a}}{R T}\right) f(\alpha)
$$

where $\mathrm{k}_{0}$ is the pre-exponential factor, $\mathrm{E}_{\mathrm{a}}$ is the activation energy, $\mathrm{R}$ is the gas constant and $\mathrm{T}$ is the absolute temperature. In DSC measurements, the vulcanization degree can be related to the heat released during the reaction and calculated by $[5]$ :

$$
\alpha=\frac{Q(t)}{Q_{T}}
$$

where $\mathrm{Q}(\mathrm{t})$ is the heat released up to time $\mathrm{t}$ and $\mathrm{Q}_{\mathrm{T}}$ is the total heat released during the crosslinking reaction. In ODR measurements, the vulcanization degree can be defined as [6]:

$$
\alpha=\frac{G^{\prime}(t)-G_{\text {min }}^{\prime}}{G_{\text {max }}^{\prime}-G_{\text {min }}^{\prime}}
$$

where $G^{\prime}(t), G_{\max }^{\prime}, G_{\text {min }}^{\prime}$ are respectively the elastic modulus at time $t$, the maximum elastic modulus and the minimum elastic modulus during the reaction.

\section{Kinetic analysis methods}

In anisothermal mode, the Kissinger method assumes that the reaction rate reached the maximum at the peak temperature and determines the activation energy simply without precise knowledge of the reaction mechanism involved:

$$
\ln \left(\frac{\beta}{T_{P}^{2}}\right)=\ln \left(\frac{k_{0} R}{E_{a}}\right)-\frac{E_{a}}{R T_{P}}
$$

where $\beta$ is the heating rate and $T_{P}$ is the peak temperature. The activation energy can be determined from the slope of the plot of $\ln \left(\beta / \mathrm{T}_{\mathrm{P}}{ }^{2}\right)$ against $1 / \mathrm{T}_{\mathrm{P}}$ [7]. The Ozawa method assumes that the reaction order is a constant value independent of the heating rate at the peak temperature, and is represented by the following equation: 


$$
\ln (\beta)=\text { const }-\frac{1.052 E_{a}}{R T_{P}}
$$

By the plot of $\ln (\beta)$ against $1 / T_{P}$, the activation energy can be calculated from the slope [8]. The Friedman method is probably the most general of the differential techniques and uses the following natural logarithmic equation:

$$
\ln \left(\frac{d \alpha}{d t}\right)=\ln \left(k_{0} f(\alpha)\right)-\frac{E_{a}}{R T}
$$

By plotting $\ln (\mathrm{d} \alpha / \mathrm{dt})$ against $1 / \mathrm{T}$ for a constant vulcanization degree $\alpha$ value, the activation energy can be obtained from the slope [9]. The Flynn-Wall-Ozawa method can determine the activation energy without knowledge of reaction order:

$\ln (\beta) \cong \ln \left(\frac{k_{0} E_{a}}{R}\right)-\ln \left(\int_{0}^{\alpha} \frac{d \alpha}{f(\alpha)}\right)-5.3305-\frac{1.052 E_{a}}{R T}$

For a given value $\alpha$, the activation energy can be calculated by the plot of $\ln (\beta)$ against $1 / \mathrm{T}[10]$. The Kissinger-Akahira-Sunose method is the extension of the Kissinger method, and is represented by the following equation:

$$
\ln \left(\frac{\beta}{T^{2}}\right) \cong \ln \left(\frac{k_{0} R}{E_{a}}\right)-\ln \left(\int_{0}^{\alpha} \frac{d \alpha}{f(\alpha)}\right)-\frac{E_{a}}{R T}
$$

It determine the activation energy by the plot of $\ln \left(\beta / \mathrm{T}^{2}\right)$ against $1 / \mathrm{T}$ for a constant value $\alpha$ [11]. In isothermal mode, the integral method results in:

$$
\ln \left(t_{\alpha, i}\right)=\ln \left(\int_{0}^{\alpha} \frac{d \alpha}{f(\alpha)}\right)-\ln \left(k_{0}\right)+\frac{E_{a}}{R T_{i}}
$$

where $t_{\alpha, i}$ is the time corresponding to a degree $\alpha$ for an isothermal reaction at the temperature $T_{i}$. The activation energy can be obtained by plotting $\ln \left(t_{\alpha, i}\right)$ against $1 / T_{i}$ for a given constant $\alpha[6]$.

\section{Experimental}

\subsection{Materials}

The silicone rubbers studied in this work are originally liquid and two-part, which include three types of Liquid Silicone Rubber (LSR) provided by Bluestar Silicones

\begin{tabular}{|c|c|c|c|c|c|c|}
\hline \multicolumn{2}{|r|}{ Materials } & $\begin{array}{l}\text { Den } \\
\text { sity }\end{array}$ & $\begin{array}{c}\text { Hard } \\
\text { ness } \\
\text { Shore } \\
\text { A }\end{array}$ & $\begin{array}{c}\text { Tensile } \\
\text { stress } \\
{[\mathrm{MPa}]}\end{array}$ & $\begin{array}{c}\text { Elong } \\
\text { ation } \\
\text { at } \\
\text { break } \\
{[\%]}\end{array}$ & $\begin{array}{l}\text { Mix } \\
\text { ratio } \\
\text { A:B }\end{array}$ \\
\hline L & LSR4350 & 1.12 & 50 & 8.4 & 570 & $1: 1$ \\
\hline S & LSR4370 & 1.14 & 68 & 9.0 & 450 & $1: 1$ \\
\hline $\mathrm{R}$ & TCS7550 & 1.25 & 52 & 5.5 & 200 & $1: 1$ \\
\hline $\mathrm{R}$ & M4370 & 1.43 & 55 & 3.0 & 130 & $9: 1$ \\
\hline
\end{tabular}
and three types of Room Temperature Vulcanization (RTV) silicone rubbers provided by Wacker Chemie.

Table 1. Main properties of silicone rubbers studied

\begin{tabular}{|c|c|c|c|c|c|c|}
\hline $\mathrm{T}$ & $\mathrm{M} 4641$ & 1.07 & 43 & 4.5 & 300 & $10: 1$ \\
\cline { 2 - 7 } $\mathrm{V}$ & $\mathrm{M} 4670$ & 1.28 & 55 & 5.5 & 250 & $10: 1$ \\
\hline
\end{tabular}

The main properties of these rubber materials are summarized in Table 1.

\subsection{DSC tests}

Differential scanning calorimetry tests were performed on Setaram DSC 92. The mixture of silicone rubbers was heated from 25 to $200{ }^{\circ} \mathrm{C}$ at various heating rates from 1 to $20{ }^{\circ} \mathrm{C} / \mathrm{min}$. The samples were about $46 \mathrm{mg}$. The dynamic heat flow signals were recorded during the heating cycle.

\subsection{ODR tests}

The vulcanization measurement of silicone rubbers was carried out in dynamic mode using a rotational rheometer HAAKE MARS III with a plate-and-plate geometry of a diameter $20 \mathrm{~mm}$. The crosslinking reaction of silicone rubbers were characterized by mean of elastic modulus curves obtained under isothermal conditions. Test temperatures used were from 100 to $140{ }^{\circ} \mathrm{C}$ for LSR and from 70 to $100{ }^{\circ} \mathrm{C}$ for RTV. The distance between the two plates is $0.5 \mathrm{~mm}$ and the frequency used in the measurement is $1 \mathrm{~Hz}$ with a deformation of $1 \%$.

\section{Results and discussion}

\subsection{Kinetic curves}

The kinetics curves of reaction rate versus temperature at different heating rates obtained by DSC measurements for silicone rubber LSR4350 are shown in Fig. 1. It is clear that the peak temperature increased with increasing heating rate.

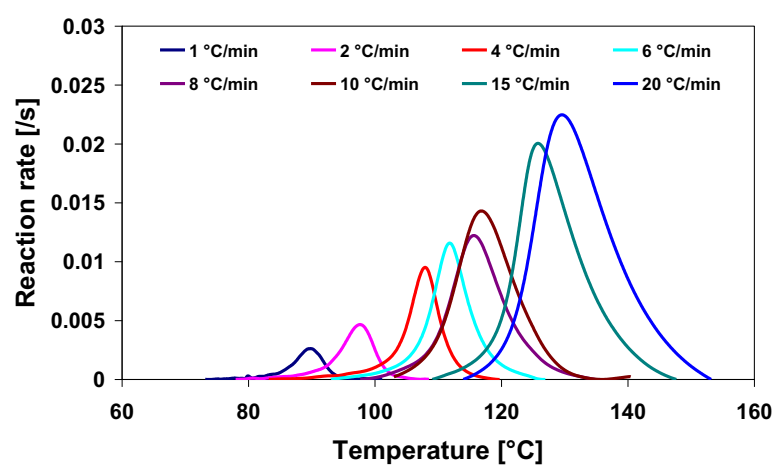

Figure 1. Kinetic curves at different heating rates for silicone rubber LSR4350 obtained by DSC measurements

The evolution of reaction degree versus time at different temperatures obtained by ODR measurements for silicone rubber LSR4350 are illustrated in Fig. 2. It appears that the variation of vulcanization time records an exponential decrease with the increasing temperature for the rubber materials. 


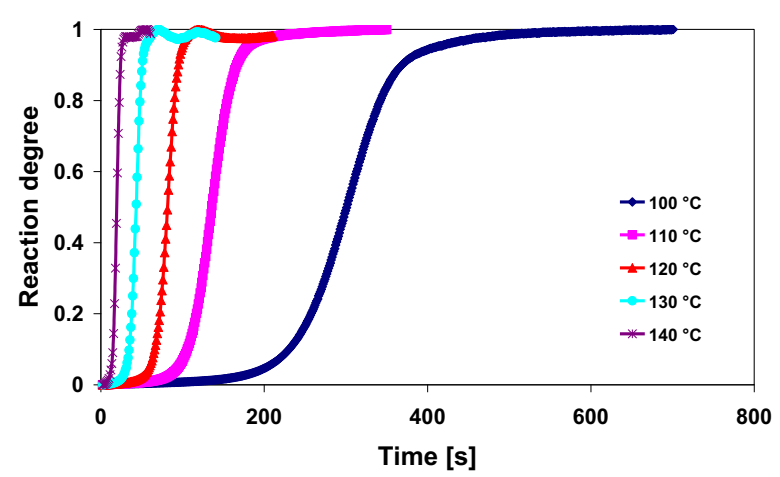

Figure 2. Kinetic curves at different temperatures for silicone rubber LSR4350 obtained by ODR measurements

\subsection{Activation energy}

From DSC experimental data, Kissinger and Ozawa methods were employed to calculate the activation energies of silicone rubbers at the peak temperature, which are shown in Figs. 3 and 4. It appears that Kissinger and Ozawa methods fit well the results a correlation coefficient at least 0.985 . The values of activation energy were obtained from the slope and summarized in Table 2 . We can note that the activation energy of LSR are larger that those of RTV.

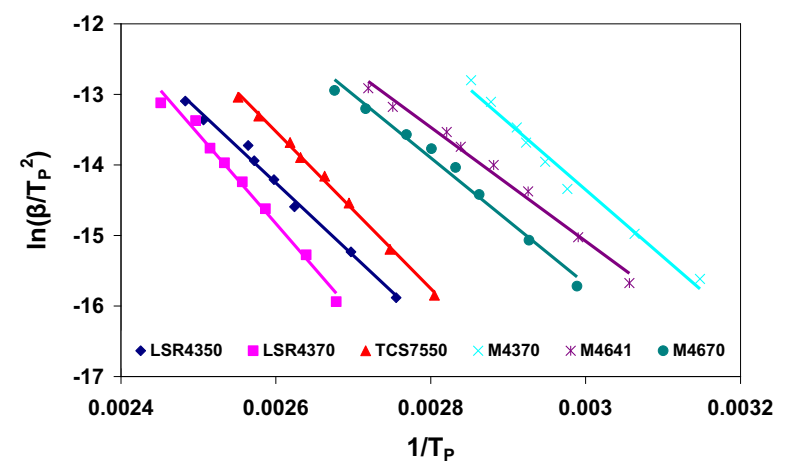

Figure 3. Kissinger plot for silicone rubbers $\left(1 / \mathrm{T}_{\mathrm{p}}: \mathrm{K}^{-1}\right)$

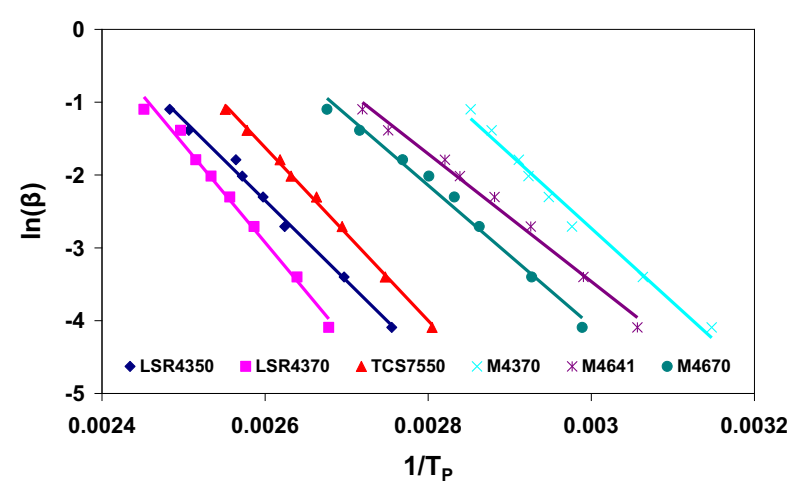

Figure 4. Ozawa plot for silicone rubbers $\left(1 / \mathrm{T}_{\mathrm{p}}: \mathrm{K}^{-1}\right)$
Table 2. The values of activation energy of silicone rubbers obtained by the Kissinger and the Ozawa methods

\begin{tabular}{|l|l|l|l|l|l|l|}
\hline \multirow{4}{*}{} & \multicolumn{6}{|l|}{$\begin{array}{l}\text { Rubber materials and values of estimated } \\
\text { activation energy [kJ/mol] }\end{array}$} \\
\cline { 2 - 7 } & LSR & LSR & TCS & M & M & M \\
& 4350 & 4370 & 7550 & 4370 & 4641 & 4670 \\
\hline $\mathbf{1}$ & 85.5 & 105.4 & 92.6 & 79.2 & 67.1 & 74.3 \\
\hline $\mathbf{2}$ & 87.3 & 78.5 & 66.8 & 68.6 & 58.9 & 64.9 \\
\hline
\end{tabular}

(Method: 1 Kissinger and 2 Ozawa)

The Friedman method, the Flynn-Wall-Ozawa method and the Kissinger-Akahira-Sunose method were also performed to calculate the activation energy of silicone rubber LSR4350 with the evolution of reaction degree, which are shown in Figs 5, 6 and 7. The values of activation energy were obtained from the slope and summarized in Fig 8. One can remark that the values obtained by the Friedman method decrease sharply from 100 to $40 \mathrm{~kJ} / \mathrm{mol}$ with the increasing of reaction degree. While the values obtained by the Flynn-Wall-Ozawa method and the Kissinger-Akahira-Sunose method are around $80 \mathrm{~kJ} / \mathrm{mol}$ for the reaction degree varying from 0.1 to 0.9 .

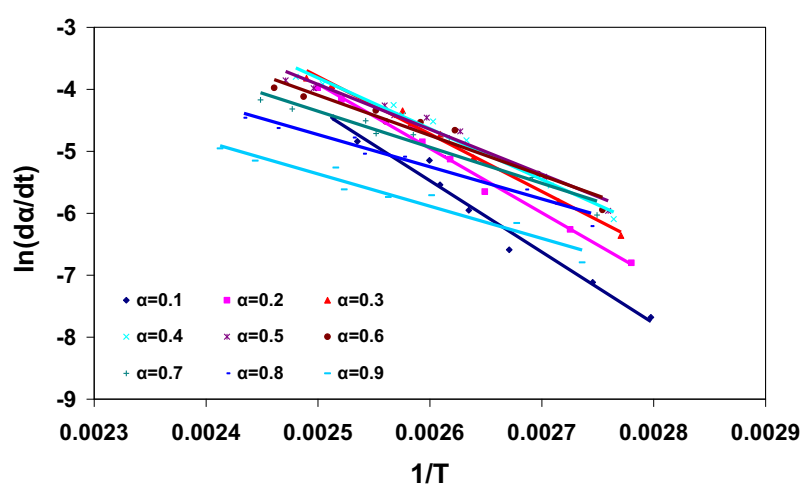

Figure 5. Friedman plot for silicone rubber LSR4350 in different reaction degrees $\left(1 / \mathrm{T}: \mathrm{K}^{-1}\right)$

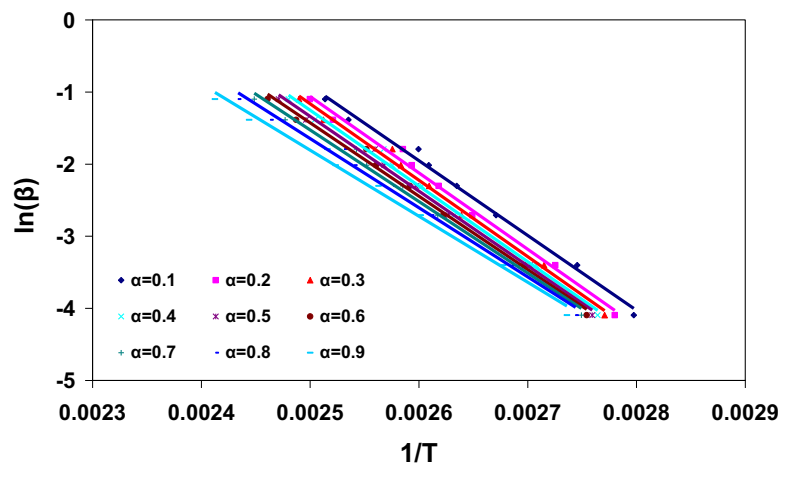

Figure 6. Flynn-Wall-Ozawa plot for silicone rubber LSR4350 in different reaction degrees $\left(1 / \mathrm{T}: \mathrm{K}^{-1}\right)$ 


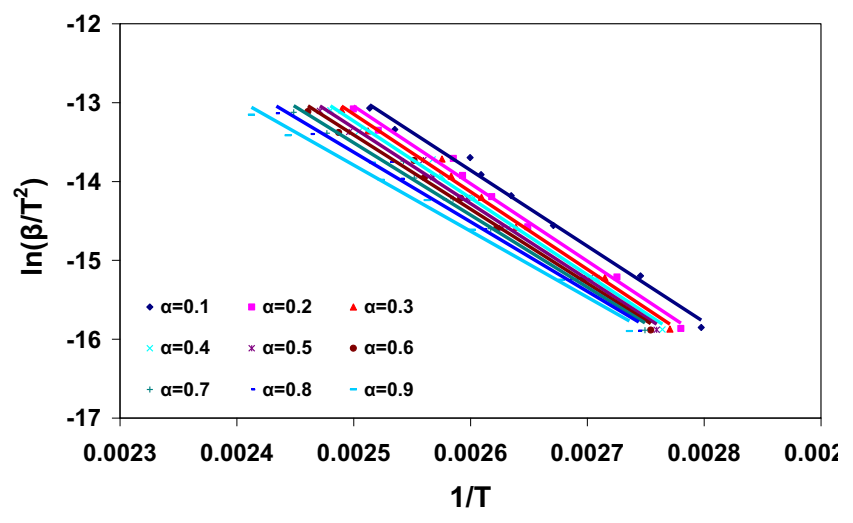

Figure 7. Kissinger-Akahira-Sunose plot for silicone rubber LSR4350 in different reaction degrees $\left(1 / \mathrm{T}: \mathrm{K}^{-1}\right)$

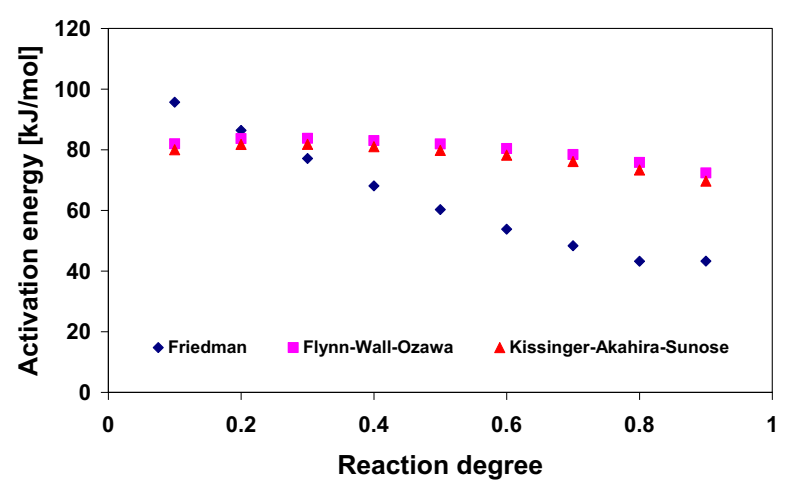

Figure 8. Evolution of the values of activation energy as a function of reaction degree for silicone rubber LSR4350 obtained by the Friedman, the Flynn-Wall-Ozawa and the Kissinger-Akahira-Sunose methods, from the kinetic curves obtained by DSC measurements

From the ODR experiment results in isothermal conditions, the integral method was applied to determine the activation energy of silicone rubber by plotting $\ln \left(t_{\alpha, i}\right)$ against $1 / \mathrm{T}_{\mathrm{i}}$ for reaction degree varying from 0.1 to 0.9 , Fig. 9. It shows that the straight lines are parallel for the different reaction degree and have a correlation coefficient over 0.99 . In Table 3 , the average values of activation energy were calculated and compared for the six types of silicone rubbers by the Friedman, the FlynnWall-Ozawa, the Kissinger-Akahira-Sunose and the isothermal integral methods. We can find that the values of activation energy of LSR silicone rubbers are always larger than those of RTV silicone rubbers. In additions, the average values obtained by ODR measurements in isothermal conditions are almost identical to those obtained by DSC measurements in anisothermal conditions.

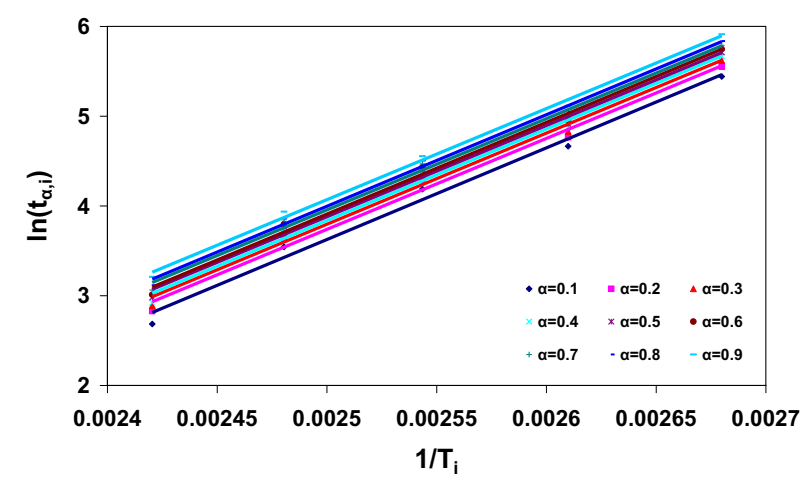

Figure 9. Isothermal integral plot for silicone rubber LSR4350 in different reaction degrees $\left(1 / \mathrm{T}_{\mathrm{i}}: \mathrm{K}^{-1}\right)$

Table 3. The values of activation energy of silicone rubbers obtained by the different kinetic analysis methods

\begin{tabular}{|c|c|c|c|c|c|c|}
\hline & \multicolumn{6}{|c|}{$\begin{array}{c}\text { Rubber materials and values of estimated } \\
\text { activation energy }[\mathrm{kJ} / \mathrm{mol}]\end{array}$} \\
\hline & $\begin{array}{c}\text { LSR4 } \\
350\end{array}$ & $\begin{array}{c}\text { LSR4 } \\
370\end{array}$ & $\begin{array}{c}\text { TCS7 } \\
\mathbf{5 5 0}\end{array}$ & $\begin{array}{c}\text { M } \\
4370\end{array}$ & $\begin{array}{c}M \\
4641\end{array}$ & $\begin{array}{c}M \\
4670\end{array}$ \\
\hline 1 & 70.1 & 85.9 & 80.3 & 61.8 & 50.4 & 54.9 \\
\hline 2 & 80.2 & 98.1 & 87.0 & 73.9 & 64.5 & 67.0 \\
\hline 3 & 77.9 & 96.7 & 85.3 & 72.2 & 62.1 & 64.4 \\
\hline 4 & 84.6 & 89.2 & 91.2 & 67.9 & 63.9 & 73.8 \\
\hline
\end{tabular}

(Method: 1 Friedman, 2 Flynn-Wall-Ozawa, 3 Kissinger-Akahira-Sunose and 4 Isothermal Integral)

\section{Conclusions}

The curing kinetic study was carried out by DSC and ODR measurements in isothermal and anisothermal conditions in order to investigate the crosslinking reaction of silicone rubbers. From the kinetic curves obtained, the kinetic parameters of activation energy were determined by six methods. The Kissinger and the Ozawa methods show that the maximum activation energies were reached at the peak temperature in anisothermal mode. In additions, the isothermal integral method almost gives the same values of activation energies as the FlynnWall-Ozawa and the Kissinger-Akahira-Sunose methods. At the end, the values of activation energy of LSR silicone rubbers were larger than those of RTV silicone rubbers studied in this investigation.

\section{References}

1. L. Wang, Q. Liu, D. Jing, S. Zhou, L. Shao, Journal of Dentistry, Progress in Organic Coatings, 42, (2014), 475-483.

2. W. Brachaczek, 77, (2014), 859-867.

3. X. Ye, H. Liu, Y. Ding, H. Li, B. Lu, Microelectronic Engineering, 86, (2009), 310313,.

4. I.K. Hong, S. Lee, vol. 19, pp. 42-47, 2013.

5. J.P. Hernández-Ortiz, T.A. Osswald, Journal of Applied Polymer Science, 119, (2011), 18641871.

6. E. Leroy, A. Souid, A. Sarda, R. Deterre, Polymer Testing, 32, 2013, 9-14. 
7. H.E. Kissinger, Reaction kinetics in differential thermal analysis, Analytical Chemistry, 29, (1957), 1702-1706.

8. T. Ozawa, Journal of Thermal Analysis, 2, (1970), 301-324,

9. H.L. Friedman, Journal of Polymer Science Part C, 6, (1964), 183-195.

10. J.H. Flynn, Journal of Thermal Analysis, 27, (1983), 92-102.

11. T. Akahira, T. Sunose, Research report, Chiba Institute of Technology, Journal of Science Education and Technology, 16, (1971), 22-31. 